\title{
1 Evidence for Amazonian mid-latitude glaciation on Mars from impact crater
}

2 asymmetry

3 Susan J. Conway* and Nicolas Mangold

4 Laboratoire de planétologie et géodynamique, CNRS UMR 6112, Université de Nantes, 2 rue

5 de la Houssinière, BP 92208, 44322 Nantes Cedex 3, France

6

7 Corresponding author's present contact details:

8 Department of Physical Sciences, Open University, Milton Keynes MK7 6AA. UK

9 tel: +44 1908655759 susan.conway@open.ac.uk

$10 *$ corresponding author 


\section{Abstract}

We find that craters slopes in the mid-latitudes of Mars have a marked north-south asymmetry, with the pole-facing slopes being shallower. We mapped impact craters in two southern hemisphere sites (Terra Cimmeria and Noachis Terra) and one northern hemisphere site (Acidalia Planitia) and used elevation data from the High Resolution Stereo Camera (HRSC) onboard Mars Express to find the maximum slope of the impact crater's walls in the four cardinal directions. Kreslavsky and Head (2003) using Mars Orbiter Laser Altimeter (MOLA) track data found that, in general, conjugate slopes are shallower in the pole-facing direction, but over a narrower $\left(\sim 10^{\circ}\right)$ and more constrained latitude band. They linked the asymmetry to active-layer formation (thaw) at high obliquity. However, Parsons and Nimmo (2009) studied crater asymmetry using MOLA gridded data and found no evidence of a relationship between crater asymmetry and latitude. Our work supports the observations of Kreslavsky and Head (2003), and shows that asymmetry is also found on conjugate crater slopes below the resolution of MOLA, over a wider latitude band than found in their work. We do not systematically find a sudden transition to asymmetric craters with latitude as expected for thaw-related processes, such as solifluction, gelifluction, or gully formation. The formation of gullies should produce the opposite sense of asymmetry to our observations, so cannot explain them despite the mid-latitude location and pole-facing preferences of gullies. We instead link this asymmetry to the deposition of ice-rich crater deposits, where the base of pole-facing slopes receive ten to hundreds of meters of additional net deposition, compared to equator-facing ones over the mid-latitudes. In support of this hypothesis we found that craters in Terra Cimmeria that have deposits on both their floor and pole-facing walls, occur preferentially at the mid-latitudes and have marked positive asymmetry. These deposits were likely laid down during high obliquity excursions $\left(>45^{\circ}\right)$ at least $5 \mathrm{My}$ ago and potentially over the whole Amazonian epoch. 
KEYWORDS: Mars, Surface; Cratering; Mars, climate; Ices

\section{Highlights}

- Pole-facing slopes are shallower from HRSC elevation between 30 and 50 ${ }^{\circ} \mathrm{N} / \mathrm{S}$.

- The N-S asymmetry is best explained by preferred deposition of ice-rich deposits on the pole-facing slope.

- These deposits were laid down at high obliquity during the Amazonian.

\section{Introduction}

The morphology of the surface of Mars is dominated by impact craters, which are continually added to its surface. After emplacement craters are modified by active surface processes and thus if global trends can be observed in crater morphology then information can be obtained about the active processes and therefore past climate (e.g., Craddock et al., 1997; Mangold et al., 2012). Kreslavsky and Head (2003) found using 0.3 km baseline MOLA (Mars Orbiter Laser Altimeter) data that pole-facing slopes are shallower than equator-facing ones over the mid-latitudes $\left(40-50^{\circ} \mathrm{N}\right.$ and S). They attributed this slope asymmetry to the thawing of ground ice under high obliquity conditions.

In contrast Parsons and Nimmo (2009) modeled the expected asymmetry due to longterm viscous creep of ground ice forced by insolation-driven variations in temperatures and found that this produced pole-facing slopes that were steeper than equator-facing ones. To validate their results they measured the slope asymmetry of 120 craters in both hemispheres (diameters of 16-40 km) using MOLA gridded data. This method has potential advantages over the Kreslavsky and Head (2003) one, because conjugate slopes within craters are the same age and on average craters are symmetrical on formation. However, the observations of Parsons and Nimmo (2009) showed no systematic pattern in crater wall slope asymmetry contrary to the predictions of their numerical model and the observations of Kreslavsky and Head (2003). They attribute the discrepancy between their asymmetry measurements and 
61 those of Kreslavsky and Head (2003) to either a lack of small craters in their study, or to different slope processes being active in craters compared to those on other types of slopes. The distinction between the different hypotheses proposed by these two groups of authors is important for the following reasons. Firstly, relaxation of crater-form through longterm deformation (Parsons and Nimmo, 2009) strongly implies the presence of tens to hundreds of meters of ice-rich regolith at or very near the surface for periods of 100,000 years or more. However, deformation of crater shape through repeated episodes of thaw concentrated on pole-facing crater walls, as described by Kreslavsky et al. (2008), only requires: a) the top few meters of the surface to be ice-rich and b) does not necessarily require this ice to be permanent, just present when warmer conditions occur. These two hypotheses have very different implications for the martian water cycle and the reservoir of water ice over the Amazonian. The first hypothesis implies that a large and shallow cryosphere has been present on Mars for long periods of the Amazonian, whereas the second implies only temporary and superficial water ice, possibly resulting from exchange with the atmosphere. To attempt to resolve these conflicting results we revisit this mid-latitude zone in Terra Cimmera, Noachis Terra and Acidalia Planitia and analyze the slopes within all resolvable craters using HRSC (High Resolution Stereo Camera) data (Fig. 1). The higher resolution ( 100 m compared to $\sim 450 \mathrm{~m}$ ) of this dataset compared to MOLA allows us to study smaller craters. We decided to measure conjugate slopes inside craters so as to assess slopes with the same age, hence same time of exposure to surface processes. This enables us to compare rates of crater wall degradation with orientation and determine if different processes have been acting according to exposure orientation.

\section{Methods}

All available level 4 HRSC elevation data on ESA's Planetary Science Archive (Scholten et al., 2005) with a resolution of $125 \mathrm{~m}$ or better and accompanying orthorectified images were 
used in the three areas spanning the maximum latitude range possible. The elevation data use the GMM3 Aeroid as a vertical reference (Gwinner et al 2008). Table 1 lists the images and elevation data resolutions for each study area. The elevation data were reprojected into a sinusoidal projection having a central meridian at the center of each study area $\left(155^{\circ}\right.$ for Terra Cimmeria, $10^{\circ}$ for Noachis Terra and $351^{\circ}$ for Acidalia Planitia). The elevation data were resampled to a constant pixel resolution of $75 \mathrm{~m} /$ pixel and where there was data overlap the data with higher resolution and/or better quality were used to avoid sampling craters in these areas twice. We chose this resolution as a compromise: to preserve information from the $50 \mathrm{~m} /$ pix data and so as not to heavily oversample the 100-125 m/pix data. The crater catalog MA130301GT (Salamuniccar et al., 2011) was used as a basis for mapping of craters down to $0.75 \mathrm{~km}$ in diameter. Impact craters visible in the images and hillshade model of the elevation data were digitized as circles in the sinusoidal projection of each study area. Craters that are obviously oblate were excluded from the survey. The center was computed from this circle for each crater and the distance and direction of each elevation pixel from the cratercenter was calculated.

Errors in the elevation data stem from two sources: firstly the internal elevation uncertainty derived from the stereo-photogrammetric method and secondly the error introduced by superposing adjacent strips. Absolute deviation of the HRSC elevation data from the MOLA spot heights is reported to be on the order of $29 \mathrm{~m}$ with a standard deviation of $41 \mathrm{~m}$ (Gwinner et al., 2009) and this corresponds well to the magnitude of the noise that we observe in our HRSC data. HRSC level 4 products can have significant shift and rotation between adjacent strips (Dumke et al. 2008). Where our craters intersected with boundaries between HRSC strips we did not find horizontal misalignment greater than 1 pixel. However, we found the average elevation differences between overlapping elevation data strips in the 
Terra Cimmeria region to be between $0.7 \mathrm{~m}$ and $9.3 \mathrm{~m}$ with a standard deviation of between 15 and $42 \mathrm{~m}$.

To account for these uncertainties and the natural variability in crater shape we analyzed the topographic trends in quadrants of the crater, rather than in individual line-profiles. HRSC elevation noise has a normal distribution centered on the 'real' elevation value (Gwinner et al., 2009); hence average profiles calculated from the data within crater quadrants are more robust than single line-profiles are to these errors. The data within 1.25 crater diameters of the crater center were extracted for further analysis. These data were divided into quadrants, north-, south-, east- and west-facing. We calculated the worst-case meridional distortion by taking the furthest crater from the projection center at the highest latitude $\left(125 \mathrm{~km}\right.$ and $72^{\circ} \mathrm{S}$ in Noachis Terra) and took the angular difference between true north and the map-projected north from the map. At worst the meridional distortion introduced by the projection system was $\sim 5.7^{\circ}$ from the true north direction at the edges of the study regions. So in the worst case $6 \%$ of the pixels ( $5.7^{\circ}$ span of a $90^{\circ}$ segment) included to calculate the average profile could be incorrectly assigned. Only if these data were consistently and systematically different from their neighbors (i.e. greater than the noise, $\sim 40 \mathrm{~m}$ ) would they shift the mean profile, hence we considered this error as negligible. For each of these quadrants the mean elevation and its standard error were calculated in $75 \mathrm{~m}$ distance bins (Fig. 2). The standard error on the mean follows. Firstly a weighted linear model was fitted to each point and its two nearest neighbors and the gradient and standard error of the gradient were recorded. The weights were 
proportional to the inverse of the standard error on the mean elevation for those points.

Secondly the maximum positive gradient value was taken as the maximum crater slope on the crater wall and its associated standard error was recorded. The slope calculated is therefore an estimate of the maximum slope at length-scales of $150 \mathrm{~m}$. The crater wall was defined as the interval between the position of maximum curvature and the rim (Fig. 2). The rim was assumed to be the highest point on the profile or at the distance given by the circle-radius if no maximum could be found before the end of the profile.

The asymmetry, "A", of the slopes was calculated similarly to Parsons and Nimmo (2009), but considering equator- and pole-facing slopes rather than north- and south-facing ones:

$$
A=S_{e q}-S_{p} / S_{a v g}
$$

where $S_{e q}$ is the equator-facing slope, $S_{p}$ the pole-facing and $S_{a v g}$ the average of the N-, S-, Eand W-facing slopes. Using this system, an equator-facing slope which is steeper than a polefacing slope leads to a positive value of $A$ in both hemispheres. The error in $A\left(\sigma_{A}\right)$ is estimated using propagation of errors, as follows:

$$
\sigma_{A}=\left(\sqrt{ }\left({\sigma_{s e q}}^{2}+{\sigma_{s p}}^{2}\right)\right) / S_{\text {avg }}
$$

where $\sigma_{\text {seq }}$ is the standard error for the equator-facing slope and $\sigma_{s p}$ is the standard error estimated for the pole-facing slope, both derived from the fitting of the weighted linear model as described above. The estimates of error on the mean $\left(\sigma_{A m n}\right)$ of asymmetry per latitude bin presented in Table 2 were derived by propagating the individual errors of $A\left(\sigma_{A}\right)$ as follows:

$$
\sigma_{A m n}=\frac{\sqrt{\sum_{i=0}^{n}\left(\sigma_{A i}^{2}+\sigma_{A i+1}^{2}+\sigma_{A i+2}^{2}+\cdots\right)}}{n}
$$

\section{To provide an estimate of regional slope the median value of the topography was taken}

between 1.4 and 1.5 crater radii for each quadrant. The difference in elevation was then taken between the equator- and pole-facing, and the W- and E-facing quadrants and normalized by 
the crater's radius. For the analysis of the asymmetry data, craters superposed on strong regional slopes were excluded. A strong regional slope was defined as a normalized difference in elevation of greater than $5 \%$.

\section{Results}

In Terra Cimmeria we mapped 567 craters between 0.75 - 39 km diameter, 664 craters between 0.75 - 68 km diameter in Noachis Terra and in Acidalia Planum 687 craters between 0.75 - $46 \mathrm{~km}$ diameter. The latitudinal evolution of the maximum slope of crater walls for each region is shown in Fig. 3a. The propagated error on the mean for the slope measurements is less than $0.003(\mathrm{~m} / \mathrm{m})$ for all latitude bins with more than 20 craters over all study zones in Fig. 3a (Table 2). In general agreement with previous global studies using MOLA data (Kreslavsky and Head, 2003), we also find that the slopes of crater walls decrease towards the high latitudes (Fig. 3a). This decrease is gradual in Acidalia Planum and Terra Cimmeria, but abrupt in Noachis Terra. Median slope values dip below 0.18 in Noachis Terra at $35^{\circ}$ latitude, whereas values below 0.18 are not found until $50^{\circ}$ latitude in Acidalia Planum and Terra Cimmeria. At latitudes greater than $55^{\circ}$ craters in all regions have slopes of $\sim 0.18$. In contrast, below $30^{\circ}$ of latitude, slopes stretch between $\sim 0.3$ and $\sim 0.5$, which are typical of fresh craters (e.g., Mangold et al., 2012).

Figure 3b shows how the asymmetry of crater walls changes with latitude. Each region has a different pattern, but each has marked positive asymmetry (steeper equator-facing slopes) in the mid-latitudes. The propagated error on the mean for the asymmetry measurements is on average 0.01 (and always less than 0.03) for all latitude bins with more than 20 craters for all study zones in Fig. 3b (Table 2). There is a strong scattering of the data for all three regions studied. This effect is expected because of the natural variability of impact crater shape from differences in formation processes and bedrock. As craters at equatorial latitudes $\left(\leq 22.5^{\circ}\right)$ have high slopes typical of weakly degraded fresh craters, we 
have used these regions to estimate the natural variation in asymmetry. Taking all the craters at these latitudes $(n=162)$, the median value $(-0.02)$ has a standard error of asymmetry of \pm 0.03 , corresponding to a $95 \%$ confidence limit of \pm 0.06 (calculated by multiplying the standard error by 1.96, the position of 95\% area under the normal distribution). Hence, a median asymmetry value $>|0.06|$ is a significant signal (when the number of craters sampled is large, see Table 2) and thus linked to crater degradation, rather than natural variability. The fact that asymmetry is systematically positive for most mid-latitude regions is consistent with this interpretation.

A more detailed inspection shows that, in Terra Cimmeria, the mean and median asymmetry changes smoothly, with positive asymmetry between $50^{\circ}$ and $30^{\circ}$, which peaks at $45^{\circ}$ and a small negative asymmetry at $55^{\circ}$. This asymmetry variation is similar to that predicted by relaxation of $\sim 100$ m of creeping permafrost (Parsons and Nimmo, 2009), but has the opposite sign, as discussed in more detail in Section 4. In Noachis Terra craters have positive mean and median asymmetry at $65^{\circ}, 50^{\circ}$ and $40-25^{\circ}$ and marked negative asymmetry at $15-10^{\circ}$ and $60^{\circ}$ and a small negative asymmetry at $55^{\circ}$. The negative anomalies at 55-60 in Noachis Terra and Terra Cimmeria will be discussed further in Section 4.3. Acidalia Planum has positive median and mean asymmetry from $50^{\circ}$ to $40^{\circ}$ and negative values at $10^{\circ}$. Absolute mean and median values are lower than for the two previous regions, and only slightly above 0.06 at latitudes from 50 to $40^{\circ}$, suggesting that this region is less affected by the process creating asymmetry.

A comparison between Figs. 3a and 3b shows that the asymmetry is an intrinsic parameter that does not depend on the slope value. For example, between $30^{\circ}$ and $50^{\circ}$ in Terra Cimmeria, there is continuous positive asymmetry and the slopes range from $\sim 0.25$ to 0.4. Figure 4 shows how the asymmetry is expressed for different sizes of craters between the latitudes of 27.5 to $42.5^{\circ}$ where the asymmetry is high for two of the regions (Fig. 3b). 
209 Craters between 1.5 and $8 \mathrm{~km}$ have the most marked asymmetry (>> 0.1) for the two southern 210 hemisphere regions. Craters at 0.5-1.0 km and 4-16 km in Acidalia Planum have weakly

211 positive asymmetry, but unlike the other two regions this latitude zone does not have strong 212 asymmetry in Fig. 3b, so we will not discuss this region further in this context. Craters larger 213 than $8 \mathrm{~km}$ and smaller than $1 \mathrm{~km}$ in Terra Cimmeria have no significant asymmetry. All craters in Noachis Terra have positive asymmetry, with the least asymmetric craters being in the $0.5-1.5 \mathrm{~km}$ diameter range.

The variation of asymmetry with depth to diameter ratio (d:D) for the three study zones is shown in Fig. 5 in the latitude zone 27.5 to $42.5^{\circ}$ (as for Fig. 4). Craters with d:D $>0.1$ in Acidalia Planum have weakly positive mean and median asymmetry and the other craters have no significant values of asymmetry. In both Terra Cimmeria and Noachis Terra craters with d:D $>0.05$ have asymmetry $>0.1$ and craters with $\mathrm{d}: \mathrm{D}<0.025$ are less asymmetric. The main difference between the two regions is for craters with d:D range of 0.025-0.05: craters in Terra Cimmeria have no significant asymmetry whereas those in Noachis Terra have a mean and median asymmetry between 0.1 and 0.2 .

\section{Implications and discussion}

\subsection{Comparison with previous work}

We compared our results to the asymmetry predicted by the modeling of viscous creep performed by Parsons and Nimmo (2009). They modeled the creep of an ice-rich layer of 3 different thicknesses (50, 100 and 150 m, dotted curves in Fig. 3b) in a 30 km diameter crater using varying obliquity (Laskar et al., 2004) over the last $100 \mathrm{My}$. For the temperature-wave to affect the depth over which deformation by ice creep occurs there must be significant differences in year-average insolation between the equator- and pole-facing slopes. Yearaverage insolation is greatest on equator-facing slopes, and at higher obliquities the magnitude of the difference decreases. The negative asymmetries found by Parsons and 
234 Nimmo (2009) result from deformation with an average obliquity of $34^{\circ}$. However, we find significant positive asymmetry, rather than negative in the latitude range predicted by their model in all of our study regions (Fig. 3b). Despite the sign being reversed it is important to note that the magnitude of the asymmetry observed approaches that predicted by their model for a deforming layer 150 m thick in Terra Cimmeria and Noachis Terra. This observation will be discussed in more detail in Section 4.3.

In contrast, the sense of the asymmetry and its latitudinal location from our study are in agreement with the results of Kreslavsky and Head (2003) (green or grey bars, Fig. 3), but there is a broader zone of asymmetry in our study areas (Fig. 3b). This may be explained by the different methods used to measure asymmetry. Kreslavsky and Head (2003) considered the distribution of all north- and south-facing slopes within 14x14 km cells, whereas we considered conjugate craters slopes at a range of different length-scales (from 1-150 km).

Kreslavsky and Head (2003) explained their observations by invoking the melt or the deformation of an active layer (Kreslavsky et al., 2008) on pole-facing slopes at high obliquity. Although year-average insolation is still greatest on equator-facing slopes at high obliquities, at obliquities above $\sim 30^{\circ}$ (depending on the slope inclination) day-average insolation is greater on the pole-facing slope (e.g., Costard et al., 2002).

In summary, considering the processes presented in these two models the asymmetry we have measured can only come about if temperatures are greater on the pole-facing, compared to the equator-facing slope, in the mid-latitudes. Ice-creep as modeled by Parsons and Nimmo (2009) produces steeper pole-facing slopes at any average obliquity up to $50^{\circ}$ and the process of thaw/active layer formation as proposed by Kreslavsky et al. (2008) only produces steeper equator-facing slopes under high obliquity excursions. Hence, our observations can only be explained by periods of high obliquity if thaw is the agent of degradation. 


\subsection{Timeframe of asymmetry development}

259

260

261

262

263

264

265

266

267

Craters from 2 to $8 \mathrm{~km}$ are those which display the most asymmetry (Fig. 4). The large majority of these craters formed $>100$ My ago. The frequency of craters in this diameter bin in any of these three areas is of the timescale of 100 My (after Hartmann and Neukum, 2001). This means, that, statistically, there is no more than one $2.83-4 \mathrm{~km}$ crater younger than $100 \mathrm{My}$. Hence, the timing of the asymmetry development of these craters should be of the order of $100 \mathrm{My}$. The depth to diameter ratio (d:D) can be used a rough proxy for the degradation state of the crater (e.g. Robbins and Hynek, 2012), hence craters with large d:D values are 'fresh' and those with small d:D values are 'degraded'. The craters with the highest d:D $>0.1$ ('freshest') and the lowest d:D $<0.025$ ('degraded') in Terra Cimmeria and Noachis Terra have less pronounced positive asymmetry than those with an intermediate d:D (Fig. 5). If the development of asymmetry happened prior to the Amazonian then we would expect only 'degraded' craters to show the asymmetry, conversely if it was very recent then we would expect craters with all degradation states to exhibit asymmetry. Neither is the case, so it is likely that the asymmetry was developed during the Amazonian.

\subsection{Ice deposition as an agent of asymmetry development}

Our asymmetry observations agree with those of Kreslavsky and Head (2003) and Kreslavsky et al. (2008) and these authors propose that the asymmetry of these craters is explained by thaw processes. However, we have also observed that many of our craters contain deposits (Fig. 6), whose form and distribution could also explain the asymmetry. In this section and Section 4.4 we further explore the development of asymmetry by deposition alone and in Section 4.5 go on to explore the plausibility of the other previously proposed mechanisms.

In the deposition model pole-facing slopes are a focus for deposition of water ice from the atmosphere and equator-facing slopes either remain ice-free, or collect less ice. For this to produce asymmetry ice must be thicker at the bottom of the slope than at the top. According 
to the calculations of Parsons and Nimmo (2009) for a $30 \mathrm{~km}$ diameter crater 50-150 m of

284

285

286

287

topographic difference is needed to produce our observed magnitude of asymmetry. From our actual asymmetry observations we can make an independent estimate of the thickness of material needed to be deposited, as follows. For any given crater, we can approximate the slope of the 'pristine' (i.e. pre-deposition) crater wall by using the slope of the equator-facing crater wall $\left(S_{e q}\right)$ and approximate the length of the pristine wall $\left(L_{w}\right)$ by using the equatorfacing distance from the maximal concavity to the rim (Fig. 7). We can then simply calculate the maximum thickness of material (Th) as follows:

$$
T h=L_{w} \times\left(S_{e q}-S_{p}\right)
$$

For the 357 craters in Terra Cimmeria and Noachis Terra between $27.5^{\circ} \mathrm{S}$ and $42.5^{\circ} \mathrm{S}$ with an asymmetry $\geq 0.2$, this gives an average of the maximum Th estimate of $122 \mathrm{~m}$ with the first and third quartiles being $22 \mathrm{~m}$ and $150 \mathrm{~m}$ respectively. This is similar to the $50-150 \mathrm{~m}$ estimate of Parsons and Nimmo (2009) despite our craters having a wide range of diameters. There are two putative ice-rich deposits, which show a similar latitudinal distribution to the zones of positive asymmetry: firstly the latitude dependent mantle (LDM) and secondly ice-deposits within craters, often termed Concentric Crater Fill (CFF).

To test whether these deposits were responsible for the asymmetry we undertook a survey of all Context Camera images (CTX) at $\sim 6 \mathrm{~m} /$ pix in the Terra Cimmeria study region. We found CTX images were the only reliable way of identifying LDM, CFF or other ice deposits at the regional scale. We did not perform the same survey in Acidalia Planitia or Noachis Terra because good quality CTX images were not present at all latitudes within these areas at the time of writing. We used the criteria of Head et al. (2010) to identify ice deposits, including the presence of elongate parallel striate, arcuate ridges, sublimation pits and troughs: some examples of the deposits are shown in Fig. 6. We divided ice deposits into 
three types according to their distribution within the crater: floor deposits, deposits on the pole-facing wall and deposits on the equator-facing wall.

Figure 8 shows that there are very clear trends in ice-deposits with latitude in Terra Cimmeria. Equatorward of $32^{\circ}$ we did not find ice deposits in any crater and polewards of $38^{\circ}$ there are no craters without ice-deposits, with the exception of two fresh craters. At latitudes around $35^{\circ}$ the most common deposits are found on pole-facing walls only, then moving polewards these grade into deposits being most common on both the floor and polefacing walls at $42^{\circ}$. Finally at $55^{\circ}$ almost all craters have floor, pole- and equator-facing deposits. Craters with positive asymmetry (where pole-facing slopes are shallower than equator-facing ones) occur at latitudes where deposits are predominantly located on both pole-facing walls and on crater floors (Fig. 8). The link is substantiated by the observation that the 72 craters with both pole-facing and floor deposits have the highest asymmetry amongst all of the other deposit-configurations with an average asymmetry of 0.25 , compared to 0.07 for the 110 craters without any deposits. The negative asymmetry expressed at $55^{\circ}$ corresponds to an area where crater floors and pole- and equator-facing walls all have deposits. Negative asymmetry is also found at the same latitude in Noachis Terra and from available images, the deposits also cover the whole crater. This zone of negative anomalies corresponds to a region with a higher than average thermal inertia (Putzig et al., 2005), interpreted as "Rocks, bedrock, duricrust and polar ice". This provides additional evidence that the deposits covering these craters could be both extensive and ice-rich.

\subsection{Link with previously mapped ice deposits}

The distribution of the dissected mantle or LDM (Mustard et al., 2001) coincides with zones where we observe positive asymmetry in all three study areas (Fig. 3). In Terra Cimmeria we observed LDM "pasted-on" to pole-facing slopes in 36\% of craters and that craters with pole-facing deposits are concentrated in zones of higher positive asymmetry 
332

(Fig. 8). However, thickness estimates for the LDM are of the order of tens of meters (e.g., Mustard et al., 2001; Willmes et al., 2012) and in places up to $40 \mathrm{~m}$ (Zanetti et al., 2010). The most recent estimates of the age of the mantle from Kostama et al. (2006) range from 5 to 0.1 My. Up to six distinct stratigraphic layers were found in areas of degradation by Schon et al. (2009), who link these layers to excursions to high obliquity in the last $5 \mathrm{My}$. Hence, the surface age is younger than the estimated age of asymmetry development, as outlined in Section 4.2. Together the age and thickness of this deposit argue against its dominant role in developing asymmetry,

The zones of positive asymmetry also coincide with mapped CFF ice deposits within craters (Fig. 3; Dickson et al., 2012), which are estimated to have thicknesses of up to $1 \mathrm{~km}$ (Dickson et al., 2010). Such deposits have been previously linked to positive asymmetry for individual craters in both the northern (Kreslavsky and Head, 2006) and southern hemisphere (Head et al., 2008). Flow directions estimated for the CFF-type fills are predominantly polewards, indicating an accumulation zone on the pole-facing slope (Fig. 6A; Dickson et al., 2012). Levy et al. (2009, 2010) found that LDM superposes CFF in the northern hemisphere and is not deformed in the same way, therefore postdates CFF formation and deformation. Levy et al. (2010) estimate the age of CFF in the northern hemisphere to be older than $70 \mathrm{My}$ with ages potentially going back to $1 \mathrm{Ga}$. This is consistent with our estimate for the timing of the asymmetry development (as outlined in Section 4.2). These estimates of thickness and age are consistent with our observations, even though we accept the large margin for error on the age estimates.

Accepting ice-deposits within craters as a plausible candidate, we now examine the processes of developing asymmetry. For positive asymmetry to be developed, the slope of the pole-facing slope must be reduced compared to the equator-facing one. This cannot be done by simply placing a blanket of material of the same thickness across the pole-facing wall. 
357 Hence, on the pole-facing slope there must be either 1) less deposition at the top of the slope, or 2) removal of the deposits at the top of the slope (by sublimation), or 3) flow downhill of the deposits previously located at the top of the slope. Option 3 could be a possibility because some of our craters contain pole-facing glacier like forms (GLFs) as mapped by Souness et al. (2012) and our study areas cross the region of viscous flow features mapped by Milliken et al. (2003). Dickson et al. (2012) found that not all of their mapped ice-deposits have characteristics indicating flow (only $~ 50 \%$ in Noachis Terra and Acidalia Planitia according to their Fig. 3). Our own observations confirm those of Dickson et al. (2012); we only found 10 (out of 124 with floor deposits) that exhibited flow features in Terra Cimmeria (example in Fig. 6C). Hence, flow downhill of ice-deposits cannot be a universal mechanism for asymmetry development.

From our observations we cannot differentiate between uneven deposition on the polefacing crater wall, as opposed to deposition everywhere and removal at the crater rim. The summits of crater rims are exposed to insolation and wind from two orientations hence form both a hostile environment for ice deposition, and a favored location for ice-removal.

A deposition model explains the lack of correspondence between the latitudinal trends in crater wall slopes and their asymmetry (Fig.3) without having to invoke two different processes. The asymmetry is explained solely by differences in deposition with orientation and the slope trend by the overall amount of deposition; hence craters at higher latitude have a greater amount of infill (so lower slopes), but can still have uneven deposition (so are still asymmetric). The greatest asymmetry is observed in craters between 1.5 and 8 km (Fig. 4) and this can easily be explained by the deposition model: smaller craters tend to be completely infilled and larger craters only protect limited amount of ice near their crater wall (Fig. 6D), rather than across their whole crater floor, hence neither exhibit strong asymmetry. 
from "fresh", hence practically unfilled (deposits on the walls) to moderately filled (d:D $>0.025)$.

The deposition model can also provide an explanation as to why there are marked negative excursions at $55-60^{\circ}$ in Terra Cimmeria and Noachis Terra: from image data we find these craters are completely covered with deposits (including the rims), hence these craters are subject to universal deposition and may have undergone viscous relaxation to produce asymmetry as proposed by Parsons and Nimmo (2009).

We have shown that to develop the crater slope asymmetry, whereby pole-facing slopes are shallower than equator-facing ones in the mid-latitudes, tens to hundreds of meters of additional net deposition is required at the base of the pole-facing slope compared to the equator-facing one (Section 4.3). This implies that pole-facing slopes in the mid-latitudes have been good environments for deposition and preservation of ice-rich deposits in the Amazonian period. From our observations we cannot differentiate between a single episode of deposition followed by preservation and multiple cycles of deposition and preservation. Net deposition relies on deposition exceeding removal by sublimation or more rarely melting. Climate models suggest that deposition of ice should occur at obliquity $>45^{\circ}$ (Forget et al., 2006), with such obliquities occurring in clusters 1-2 My apart, during the time-period preceding 5.5 My ago (Laskar et al, 2002; 2004). Ice may preferentially be deposited on pole-facing slopes at high obliquity, because they have lower day-average insolation than equator-facing ones under high obliquity conditions, despite these slopes also experiencing the highest day-average temperatures in summer (Kreslavsky et al. 2008). The ice deposited during these high obliquity periods must also survive the intervening time. The lower year-average temperatures on pole-facing slopes at any obliquity compared to equatorfacing ones helps to slow the sublimation and preserve deposits there as observed in Greg crater (Hartmann et al., 2013). 


\subsection{Other candidate processes for asymmetry development}

408

409

410

411

412

413

414

415

416

417

418

419

420

421

422

423

424

425

426

427

428

429

430

431

Kreslavsky and Head (2003) and Kreslavsky et al. (2008) favored thaw-related processes to generate asymmetry, including: a) creep, in the form of active layer creep (solifluction and/or gelifluction) or b) overland flow, or debris flow associated with gullies. Kreslavsky et al. (2008) argue that the asymmetry and lack of steep slopes at high latitudes must be accounted for by thaw-processes rather than any other process for the following two reasons: 1) The transition from preservation of steep slopes to shallower slopes occurs over a very narrow band and thus must be related to a threshold process, such as melting. However, we find that this rapid transition is only observed in Noachis Terra (Fig. 3b), so this argument cannot be used in favor of thaw-related processes. 2) Steep slopes are preserved at the equator despite the evidence for glacial activity; hence flowing-ice cannot explain slope-lowering. However, this only applies a) if the deposits are no longer present and b) if the flowing ice did not experience basal melting (so non-erosive). We have found that in areas with marked positive asymmetry there are still ice-deposits present, but there is not always evidence of flow.

Hence, this argument does not preclude that cold-based, or non-moving ice-deposits could cause asymmetry, rather than thaw-processes.

Active layer creep only occurs within the top few meters of the ground and only when temperatures are above zero, and on Earth horizontal displacement rates are on the order of $10 \mathrm{~cm} / \mathrm{yr}$ or less, with annual thaw (e.g., Alexander and Price, 1980). On Mars, thaw would be less common and the distance from the rim to base of the slope is on average $1.3 \mathrm{~km}$ (range: 0.2-11.6 km). Hence, simply moving material the required distance would take 130 Earth-like thaw cycles, without considering the fact that the deposits can be 22-150 m thick. This seems unlikely, but only modeling of depth-limited creep could reveal if this amount of mass transfer was plausible over realistic timescales for the martian environment. Unfortunately the lobes and terraces which would indicate geliflucation/solifluction processes, as seen 
elsewhere on Mars (Gallagher et al., 2011; Johnsson et al., 2012) are on the decameter scale so would not necessarily be identifiable on CTX images. Hence, the role of active-layer creep in generating asymmetry cannot be completely ruled out.

Gullies are thought to be the result of overland flow or debris flow (e.g., Costard et al. 2002; Heldmann et al., 2005). Gullies occur in our study regions and are predominantly polefacing in accordance with other global-scale studies (e.g., Balme et al., 2006; Kneissl et al., 2010). Gullies are found only on steep slopes ( $>18^{\circ}$ or $0.32 \mathrm{~m} / \mathrm{m}$, Conway et al., 2012). This observation could be explained by gullies causing the steeper slopes - removal of material near the top of the slope tends to increase, rather than decrease the maximum slope angle (e.g., Ballantyne and Benn, 1994). This action would lead to negative slope asymmetry. If gullies require steep slopes to form (and do not steepen the slopes) then asymmetries developed on crater walls below 0.32 slope angle cannot be explained by gully-forming process. In either case, gullies cannot be the dominant process causing asymmetry. If gullies are associated with degradation of the thicker pole-facing ice-deposits, as suggested by Berman et al. (2005), then gullies could be an explanation for the scatter in our data in the mid-latitudes.

\section{Conclusions}

We find an asymmetry in conjugate crater wall slopes for mid-latitude regions whereby polefacing crater walls are shallower than equator-facing ones over a wide band (30-50) for our three study regions. Although the asymmetry that we observe has the same magnitude as the creep of a hundreds of meters thick ice-rich layer (Parsons and Nimmo, 2009), it has the opposite sense. Our work confirms and extends the global asymmetry observations of Kreslavsky and Head (2003) made using MOLA track data, with our data showing that conjugate crater slopes below the resolution of MOLA are also asymmetric, and this asymmetry is expressed over a wider latitude band than found in their work. These authors 
suggest that asymmetry is related to thaw processes, such as solifluction, gelifluction or gully-formation. However, we do not observe a threshold latitude of onset for the asymmetry as expected for thaw-processes. In addition, gully-formation acts to produce negative asymmetry, hence cannot explain the observations. Therefore, we propose another mechanism to produce asymmetry: the differential deposition of ice. In this model, ice-rich material is preferentially deposited at the base of the pole-facing crater wall under high obliquity periods during the Amazonian. To produce the observed asymmetry tens to hundreds of meters of additional net deposition is required on the pole-facing slope compared to the equator-facing one. This model is supported by our observation in Terra Cimmeria that the most positively asymmetric craters contain deposits on their floors or pole-facing wall. Our observations suggest that these deposits are likely to have formed throughout the Amazonian and are more likely to be similar to those previously described as Concentric Crater Fill (CFF; e.g., Dickson et al., 2012), rather than the thinner surficial latitude dependent mantle (LDM; e.g., Mustard et al. 2001).

\section{Acknowledgments}

472 We thank two anonymous authors for their insightful and detailed comments, which greatly improved this manuscript. Authors were financed by the Region Pays de Loire and the French space agency (CNES). We acknowledge the effort of HRSC team members who have contributed to the preparatory phases and DEMs calculations. We thank V. Ansan for helpful discussions and C. Souness for sharing his data on glacier like forms (GLFs).

\section{6. References}

478 Alexander, C.S., Price, L.W., 1980. Radiocarbon dating of the rate of movement of two solifluction lobes in the Ruby Range, Yukon Territory. Quaternary Research 13, 365-379. 
482 Balme, M.R., et al., 2006. Orientation and distribution of recent gullies in the southern

483

484

485

486

487

488

489

490

491

492

493

494

495

496

497

498

499

500

501

502

503

504

505

506

hemisphere of mars: Observations from High Resolution Stereo Camera/Mars Express

(HRSC/MEX) and Mars Orbiter Camera/Mars Global Surveyor (MOC/MGS) data. J.

Geophys. Res.-Planets 111, doi:10.1029/2005JE002607.

Berman, D.C., Hartmann, W.K., Crown, D.A., Baker, V.R., 2005. The role of arcuate ridges and gullies in the degradation of craters in the Newton Basin region of Mars. Icarus 178, 465-486.

Conway, S,J., Mangold, N., Balme, M.R., Ansan, V., 2012 Comparison of the morphology of crater-slopes with gullies to those without gullies. Lunar Planet. Sci. 43, Abstract 2281.

Costard, F., Forget, F., Mangold, N., Peulvast, J.P., 2002. Formation of recent Martian debris flows by melting of near-surface ground ice at high obliquity. Science 295, 110-113.

Craddock, R.A., Maxwell, T.A., Howard, A.D., 1997. Crater morphometry and modification in the Sinus Sabaeus and Margaritifer Sinus regions of Mars. J. Geophys. Res. 102, 1332113340.

Dickson, J.L., Head, J.W., Fassett, C.I., 2012. Patterns of accumulation and flow of ice in the mid-latitudes of Mars during the Amazonian. Icarus 219, 723-732.

Dickson, J.L., Head, J.W., Marchant, D.R., 2010. Kilometer-thick ice accumulation and glaciation in the northern mid-latitudes of Mars: Evidence for crater-filling events in the Late Amazonian at the Phlegra Montes. Earth Planet. Sci. Lett. 294, 332-342.

Dumke, A., Spiegel, M., Schmidt, R., Michael, G., Neukum, G., 2008. Mars: high-resolution digital terrain model and ortho-image mosaic on the basis of MEX/HRSC data. International Archives of the Photogrammetry, Remote Sensing and Spatial Information Sciences XXXVII(B4), 1037-1042.

Forget, F., Haberle, R.M., Montmessin, F., Levrard, B., Head, J.W., 2006. Formation of Glaciers on Mars by Atmospheric Precipitation at High Obliquity. Science 311, 368-371. 

and associated gullies in high-latitude craters on Mars: Landforms indicative of very recent, polycyclic ground-ice thaw and liquid flows. Icarus 211, 458-471.

Gwinner, K., et al., 2008. Archival Stereo Data Products of the HRSC Experiment Onboard Mars Express. Lunar Planet. Sci. 39, Abstract 1393.

512 Gwinner, K., Scholten, F., Spiegel, M., Schmidt, R., Giese, B., Oberst, J., Heipke, C., Jaumann, R., Neukum, G., 2009. Derivation and Validation of High-Resolution Digital Terrain Models from Mars Express HRSC Data. Photogrammetric Engineering and Remote Sensing 75, 1127-1142.

Johnsson, A., Reiss, D., Hauber, E., Zanetti, M., Hiesinger, H., Johansson, L., Olvmo, M., 2012. Periglacial mass-wasting landforms on Mars suggestive of transient liquid water in the recent past: Insights from solifluction lobes on Svalbard. Icarus 218, 489-505. latitude glaciation in the Late Amazonian period of Mars: Criteria for the recognition of debris-covered glacier and valley glacier landsystem deposits. Earth Planet. Sci. Lett. 294, $306-320$.

Head, J.W., Marchant, D.R., Kreslavsky, M.A., 2008. Formation of gullies on Mars: Link to recent climate history and insolation microenvironments implicate surface water flow origin. P. Natl. Acad. Sci. USA 105, 13258-13263. Hartmann, W.K., Ansan, V., Berman, D.C., Mangold, N., Forget, F., 2013. Comprehensive 527 Analysis of Glaciated Martian Crater Greg. Icarus, submitted. Hartmann, W.K., Neukum, G., 2001. Cratering Chronology and the Evolution of Mars. Space Sci. Rev. 96, 165-194. Heldmann, J.L., Toon, O.B., Pollard, W.H., Mellon, M.T., Pitlick, J., McKay, C.P., 531 Andersen, D.T., 2005. Formation of Martian gullies by the action of liquid water flowing 
under current Martian environmental conditions. J. Geophys. Res.-Planets 110, doi:10.1029/2004JE002261.

Kneissl, T., Reiss, D., van Gasselt, S., Neukum, G., 2010. Distribution and orientation of northern-hemisphere gullies on Mars from the evaluation of HRSC and MOC-NA data. Earth Planet. Sci. Lett. 294, 357-367.

Kostama, V.-P., Kreslavsky, M.A., Head, J.W., 2006. Recent high-latitude icy mantle in the northern plains of Mars: Characteristics and ages of emplacement. Geophys. Res. Lett. 33, doi: 10.1029/2006GL025946.

Kreslavsky, M.A., Head, J.W., 2006. Modification of impact craters in the northern plains of Mars: Implications for Amazonian climate history. Meteorit. Planet. Sci. 41, 1633-1646. Kreslavsky, M.A., Head, J.W., 2000. Kilometer-scale roughness of Mars: Results from MOLA data analysis. J. Geophys. Res. 105, 26695-26712.

Kreslavsky, M.A., Head, J.W., 2003. North-south topographic slope asymmetry on Mars: Evidence for insolation-related erosion at high obliquity. Geophys. Res. Lett. 30, doi:10.1029/2003GL017795.

Kreslavsky, M.A., Head, J.W., Marchant, D.R., 2008. Periods of active permafrost layer formation during the geological history of Mars: Implications for circum-polar and midlatitude surface processes. Planet. Space Sci. 56, 289-302.

Laskar, J., Levrard, B., Mustard, J.F., 2002. Orbital forcing of the martian polar layered deposits. Nature 419, 375-377.

Laskar, J., Correia, A.C.M., Gastineau, M., Joutel, F., Levrard, B., Robutel, P., 2004. Long term evolution and chaotic diffusion of the insolation quantities of Mars. Icarus 170, 343364. 
Levy, J., Head, J.W., Marchant, D.R., 2010. Concentric crater fill in the northern mid latitudes of Mars: Formation processes and relationships to similar landforms of glacial origin. Icarus 209(2), 390-404.

Levy, J.S., Head, J.W., Marchant, D.R., 2009. Concentric crater fill in Utopia Planitia: History and interaction between glacial "brain terrain" and periglacial mantle processes. Icarus 202(2), 462-476.

Mangold, N., Adeli, S., Conway, S.J., Ansan, V., Langlais, B., 2012. A chronology of early Mars climatic evolution from impact crater degradation. J. Geophys. Res. 117, doi:10.1029/2011JE004005.

Parsons, R.A., Nimmo, F., 2009. North-south asymmetry in Martian crater slopes. J. Geophys. Res. 114, doi:10.1029/2007JE003006.

Milliken, R.E., Mustard, J.F., Goldsby, D.L., 2003. Viscous flow features on the surface of Mars: Observations from high-resolution Mars Orbiter Camera (MOC) images. J. Geophys. Res.-Planets 108, doi:10.1029/2002JE002005.

Mustard, J.F., Cooper, C.D., Rifkin, M.K., 2001. Evidence for recent climate change on Mars from the identification of youthful near-surface ground ice. Nature 412, 411-414.

Putzig, N.E., Mellon, M.T., Kretke, K.A., Arvidson, R.E., 2005. Global thermal inertia and surface properties of Mars from the MGS mapping mission. Icarus 173, 325-341.

Robbins, S.J., Hynek, B.M., 2012. A new global database of Mars impact craters $\geq 1$ km: 1 . Database creation, properties, and parameters. J. Geophys. Res. 117, doi : 10.1029/2011JE003966.

Salamuniccar, G., Loncaric, S., Pina, P., Bandeira, L., Saraiva, J., 2011. MA130301GT catalogue of Martian impact craters and advanced evaluation of crater detection algorithms using diverse topography and image datasets. Planet. Space Sci. 59, 111-131. 
579 Schon, S.C., Head, J.W., Milliken, R.E., 2009. A recent ice age on Mars: Evidence for

580 climate oscillations from regional layering in mid-latitude mantling deposits. Geophys. Res.

581 Lett. 36, doi:10.1029/2009GL038554.

582 Scholten, F., Gwinner, K., Roatsch, T., Matz, K.-D., Wählisch, B., Giese, B., Oberst, J.,

583 Jaumann, R., Neukum, G., 2005. Mars Express HRSC Data Processing - Methods and

584 Operational Aspects. Photogramm. Eng. Remote Sens. 71, 1143-1152.

585 Souness, C., Hubbard, B., Milliken, R.E., Quincey, D., 2012. An inventory and population-

586 scale analysis of Martian glacier-like forms. Icarus 217(1), 243-255.

587 Willmes, M., Reiss, D., Hiesinger, H., Zanetti, M., 2012. Surface age of the ice-dust mantle 588 deposit in Malea Planum, Mars. Planetary and Space Science 60, 199-206.

589 Zanetti, M., Hiesinger, H., Reiss, D., Hauber, E., Neukum, G., 2010. Distribution and

590 evolution of scalloped terrain in the southern hemisphere, Mars. Icarus 206, 691-706. 
592 Table 1: HRSC image numbers used for each study area ${ }^{a}$

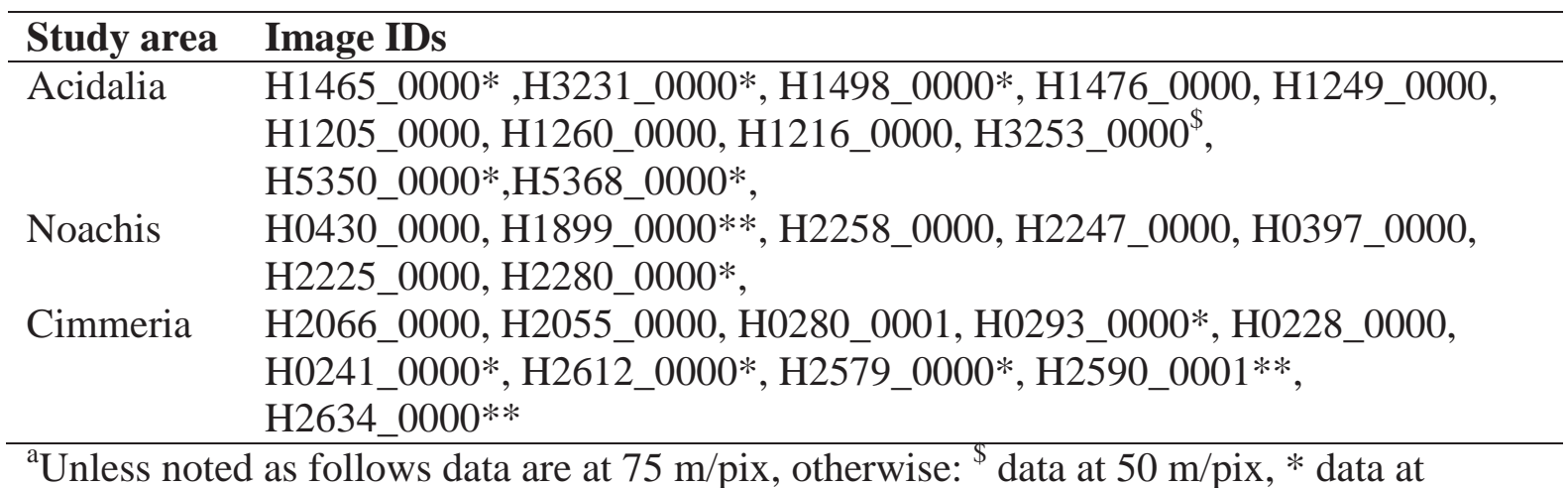

$593{ }^{a}$ Unless noted as follows data are at $75 \mathrm{~m} /$ pix, otherwise: ${ }^{\$}$ data at $50 \mathrm{~m} / \mathrm{pix}$, * data at

$594100 \mathrm{~m} /$ pix, ** data at $125 \mathrm{~m} /$ pix. The order of the images denotes the order in which they

595 were stitched, with the first of the list taking priority. 


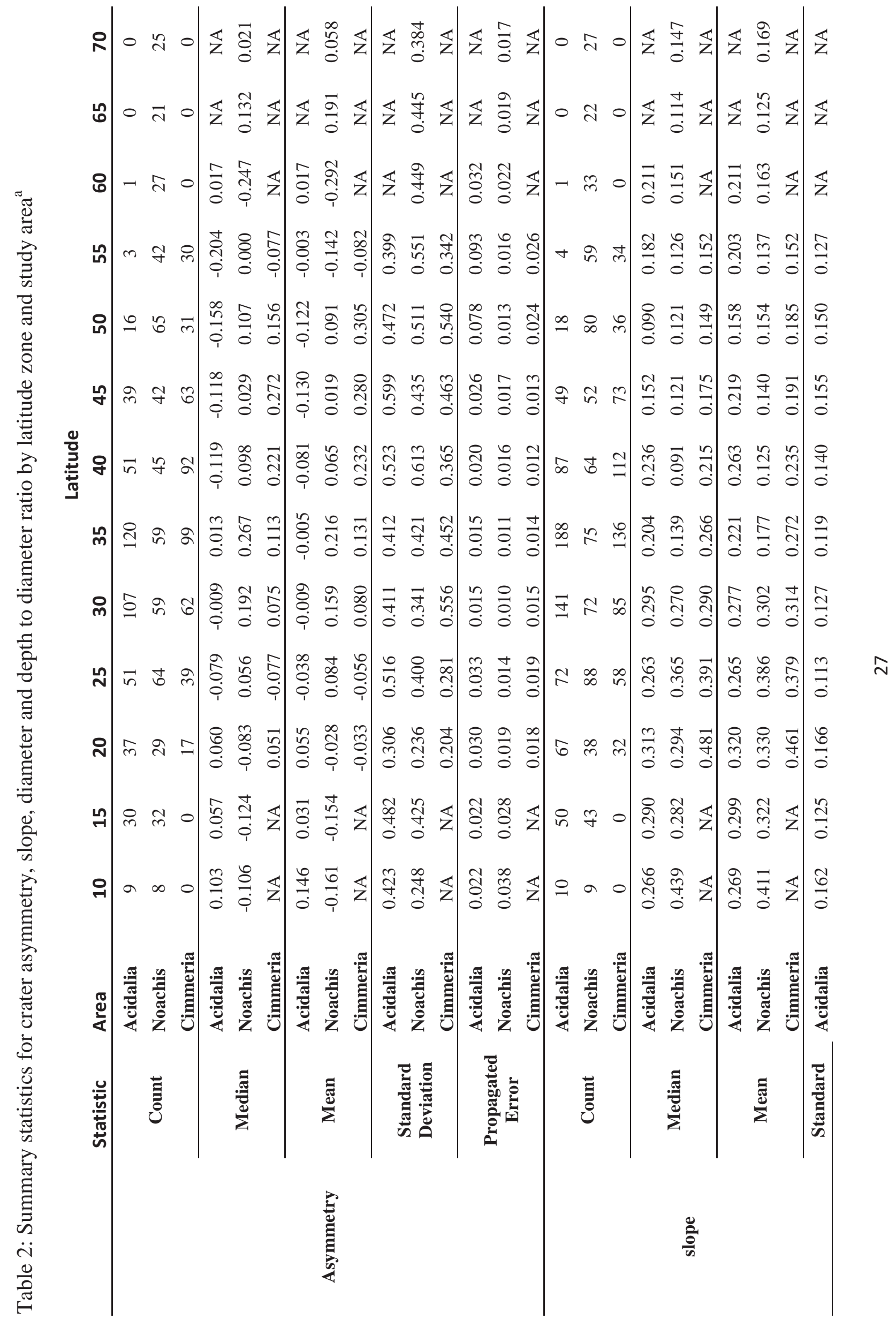




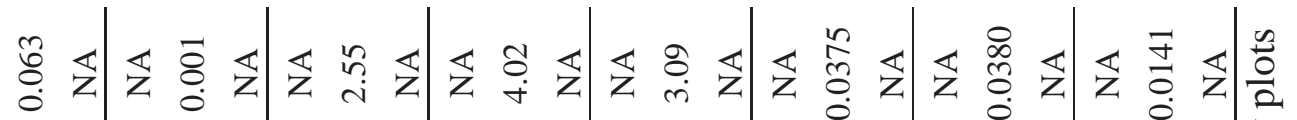

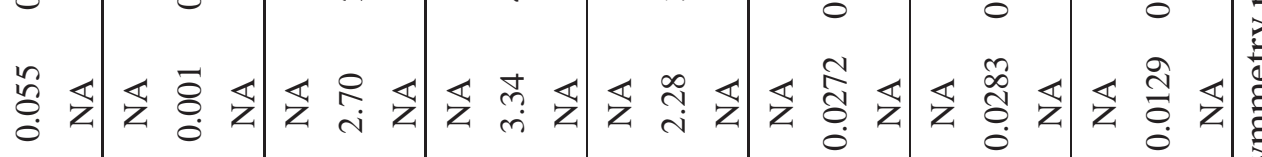

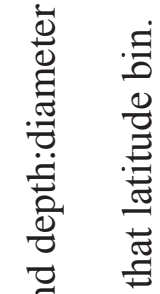

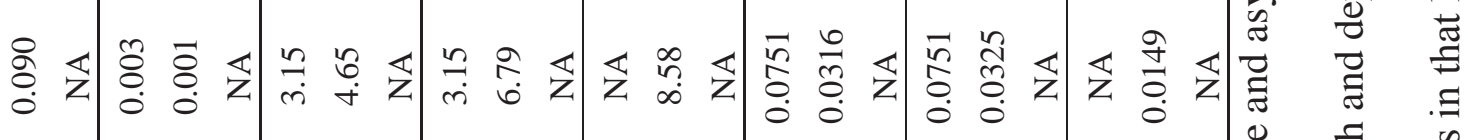

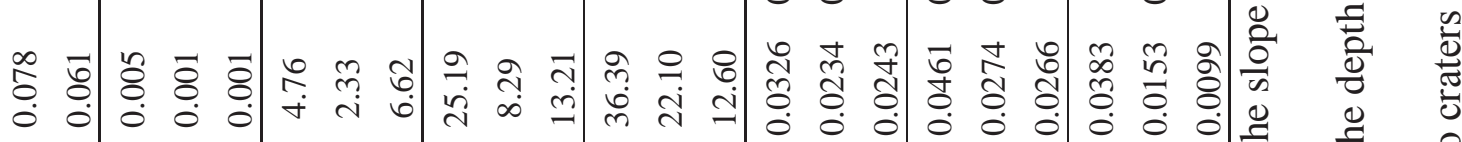

全

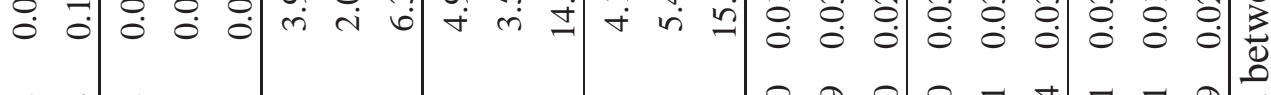

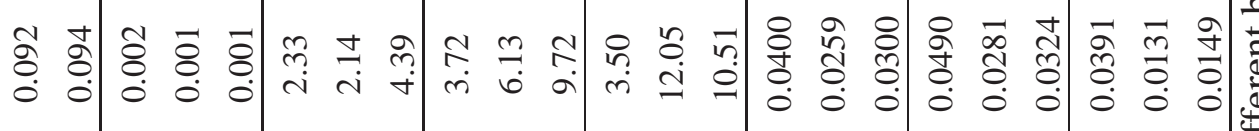

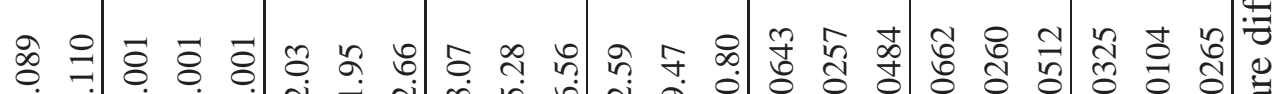

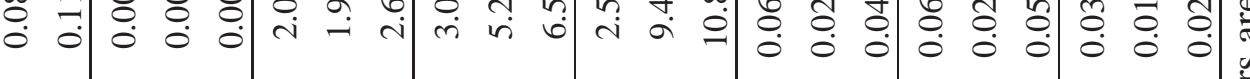

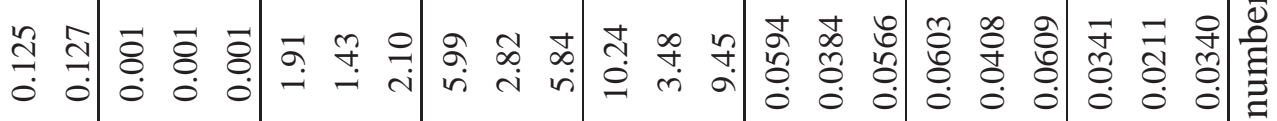

象

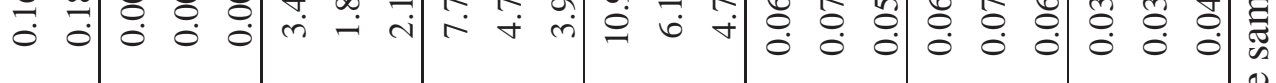

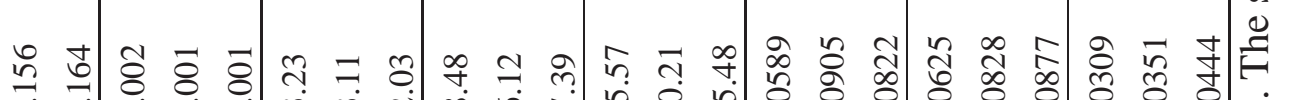
·.

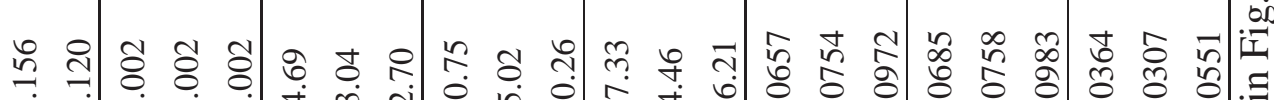

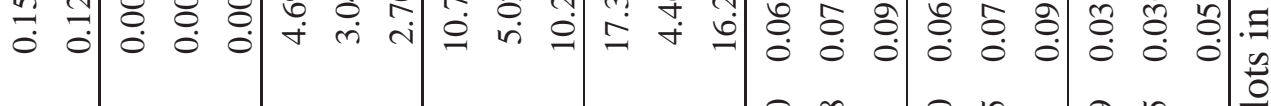

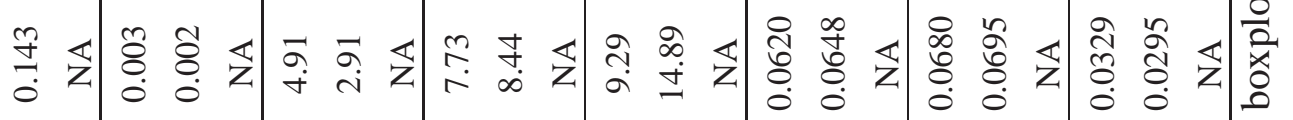

占

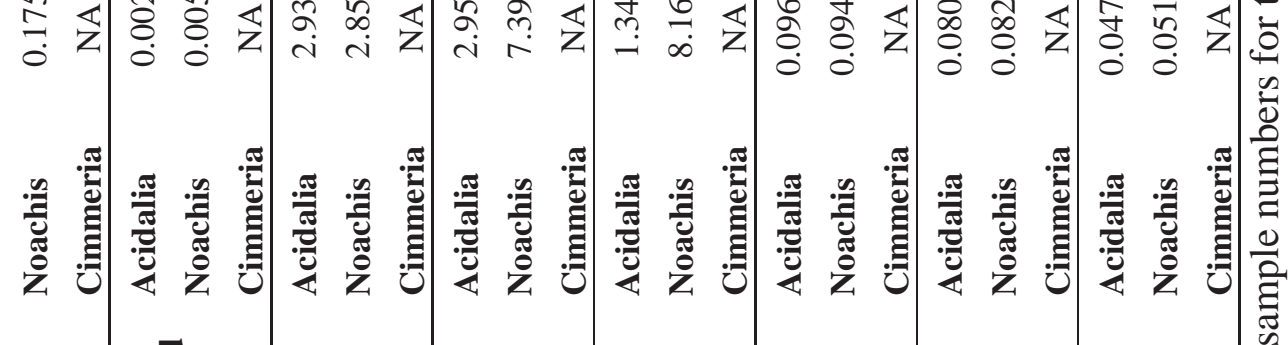

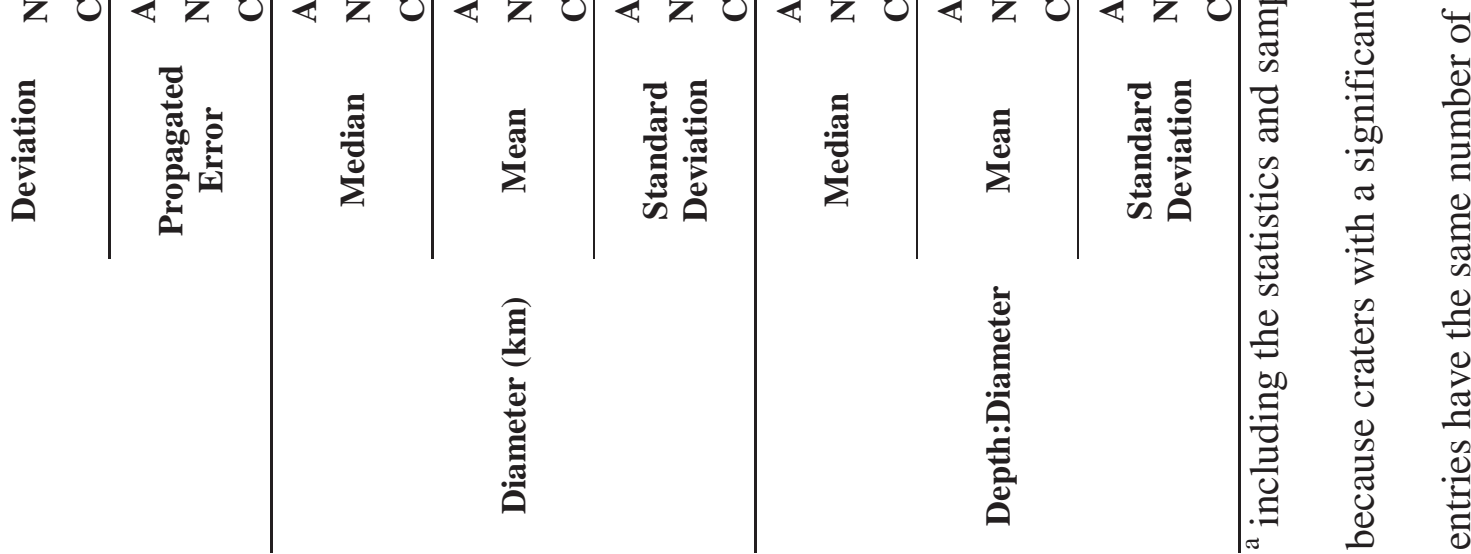

品 呑 \& 


\section{Figure Captions}

602

603

604

605

606

607

608

609

610

611

612

613

614

615

616

617

618

619

620

621

622

623

624

625

Figure 1. Study sites. "A" = Acidalia Planum, "C" = Terra Cimmeria and "N" = Noachis Terra. The outlines represent the outlines of the stitched HRSC elevation data.

Figure 2. Top: plan view of example craters in Terra Cimmeria and bottom corresponding average crater profiles for pole-facing (south-facing) crater slopes. On the left is an example simple crater $\left(35.920^{\circ} \mathrm{S}, 153.841^{\circ} \mathrm{E}\right)$ and on the right an example complex crater $\left(27.315^{\circ} \mathrm{S}\right.$, $\left.157.427^{\circ} \mathrm{E}\right)$. For the maps: HRSC images are overlain on a color-stretch of the HRSC elevation data (in online version; red is high and blue is low elevation). The crater center is marked as a dot, solid lines delimit the quadrants used to extract the profile data (at 1.5 crater radii) and dashed lines are the initial crater rim approximation. For the profiles: grey points are the raw data points from the whole quadrant, black points are the average profile and those that lie at distances less than the crater radius are filled. The standard error of each elevation point is given as vertical bars (often within the point). The black line is the straight line connecting the crater's center (positioned vertically at the measured profile minimum to ignore the central peak) to the rim. The ' $\mathrm{x}$ ' marks the horizontal distance to the maximum slope measurement and the '*' shows the position of maximum curvature (where the distance from the straight line and average profile is greatest). The simple crater from the profile on the left has a maximum slope of 0.33 and curvature of 0.03 . The complex crater from the profile on the right has a maximum slope of 0.31 and curvature of 0.16 . The Curvature is defined as the maximum distance from the straight line to the average profile normalized by rim-to-floor height.

Figure 3. Boxplots of (a) the variation of maximum crater slope with latitude and (b) crater wall asymmetry in the three study regions. Note the latitude scale is absolute, so for Acidalia 
they represent northern latitudes and for the other two sites, southern latitudes. The thick bar across each box is the mean value and the thin bar the median value, the extent of the box delimits the interquartile range, the whiskers indicate the range, while the points are outliers values which are further than 1.5 interquartile ranges from the quartiles. Sample numbers for these plots are given in Table 2. The boxes are placed on the center of their latitude range. The bars in the panel between the plots represent the latitudinal distribution of: in dark grey (yellow online) $=$ the distribution of crater ice fill as mapped by Dickson et al. (2012), in black (red online) = the boundary between the rough and smooth terrains mapped by Kreslavsky and Head (2000), in white (blue online) zones with dissected mantle noted by Mustard et al. (2001) and in grey (green online) = zones of asymmetry noted by Kreslavsky and Head (2003), “+” meaning the asymmetry was positive and "-” that it was negative. The dotted lines on (b) show the expected asymmetry of craters after 100 My of deformation of a 150 m (dash-dot, blue online), 100 m (dotted, red online) and 50 m (dashed, black) thick layer with 40\% dust as calculated by Parsons and Nimmo (2009). The grey zone delimits $A= \pm 0.06$ outside which asymmetry values are significant.

Figure 4. Asymmetry " $A$ " against crater diameter for in the region between 27.5 and $42.5^{\circ}$. Sample numbers are given below the boxes. The thick bar across each box is the mean value and the thin bar the median value, the extent of the box delimits the interquartile range, the whiskers indicate the range, while the points are outliers - values which are further than 1.5 interquartile ranges from the quartiles. The grey zone delimits $A= \pm 0.06$ outside which asymmetry values are significant. The intervals are closed on the right (i.e. 1.5-2 indicates $1.5<D \leq 2)$. 
650

651

652

653

654

655

656

657

658

659

660

661

662

663

664

665

666

667

668

669

670

671

672

673

674

Figure 5. Asymmetry " $A$ " against crater depth:diameter for in the region between 27.5 and $42.5^{\circ}$. Sample numbers are given below the boxes. The thick bar across each box is the mean value and the thin bar the median value, the extent of the box delimits the interquartile range, the whiskers indicate the range, while the points are outliers - values which are further than 1.5 interquartile ranges from the quartiles. The grey zone delimits $A= \pm 0.06$ outside which asymmetry values are significant. The intervals are closed on the right (i.e. 0.05-0.075 indicates $0.05<d: D \leq 0.075)$.

Figure 6. Examples of positively asymmetric infilled craters, all images are oriented with the pole towards the bottom of the image and the equator towards the top (arrowheads point north) and all scale bars are $1 \mathrm{~km}$. A: Crater at $40.14^{\circ} \mathrm{S}, 156.34^{\circ} \mathrm{E}$ with an asymmetry of 0.47 in Terra Cimmeria, showing evidence of flow of material away from the pole-facing wall. CTX image: P15_006894_1417. B: Crater at $43.44^{\circ} \mathrm{S}, 156.43^{\circ} \mathrm{E}$ with an asymmetry of 1.14 in Terra Cimmeria, showing no evidence of flow, but asymmetric deposition. CTX image: P17_007751_1349. C: Crater at $47.52^{\circ} \mathrm{N}, 8.68^{\circ} \mathrm{W}$ with asymmetry of 0.21 in Acidalia Planitia with classic Concentric Crater Fill (CFF), this deposit continues up onto the polefacing crater wall and it absent from the equator-facing wall. The equator-facing wall also hosts a suite of small gully-like landforms. CTX image: B21_017646_2281. D: Crater at $31.16^{\circ} \mathrm{S}, 12.92^{\circ} \mathrm{E}$ in with asymmetry of 0.09 in Noachis Terra. In this case the infill shows no evidence of being ice-rich, but deposition of material at the base of the pole-facing wall (indicated by arrows) has caused the crater to be positively asymmetric. CTX image: P17_007743_1482. CTX images courtesy of NASA/JPL-Caltech/MSSS.

Figure 7: Diagram to illustrate the calculation of thickness of deposition (Th) required to produce observed asymmetries (Eq. 4). $S_{p}$ is the slope of the pole-facing wall, $S_{e q}$ is the slope 
675 of the equator-facing wall and $L_{w}$ is the length of the equator-facing wall. If we assume that $676 S_{e q}$ is a reasonable minimum estimate of the slope of the pre-deposition crater wall, and $L_{w}$ a

677 reasonable estimate of that wall's length, we can project $S_{e q}$ downwards from the rim of the 678 pole-facing wall over a distance $L_{w}$, to estimate the additional thickness of deposition (Th) on 679 the pole-facing wall.

680

681 Figure 8: A map of craters with ice-rich deposits in the Terra Cimmeria study area aligned 682 with a copy of Fig. 3b: a boxplot showing the variation of crater asymmetry with latitude. 683 The different symbols on the map refer to different locations within the crater which host ice684 deposits, as indicated in the legend. Where the crater deposits are 'unknown', this means that 685 either, there was no CTX image available, the CTX image contained noise or cloud, or there 686 was too much shadow to clearly see the crater walls. The boxplot is a simplified version of 687 Fig. 3b where the thick bar across each box is the mean value with the extent of the box 688 delimiting the interquartile range. 


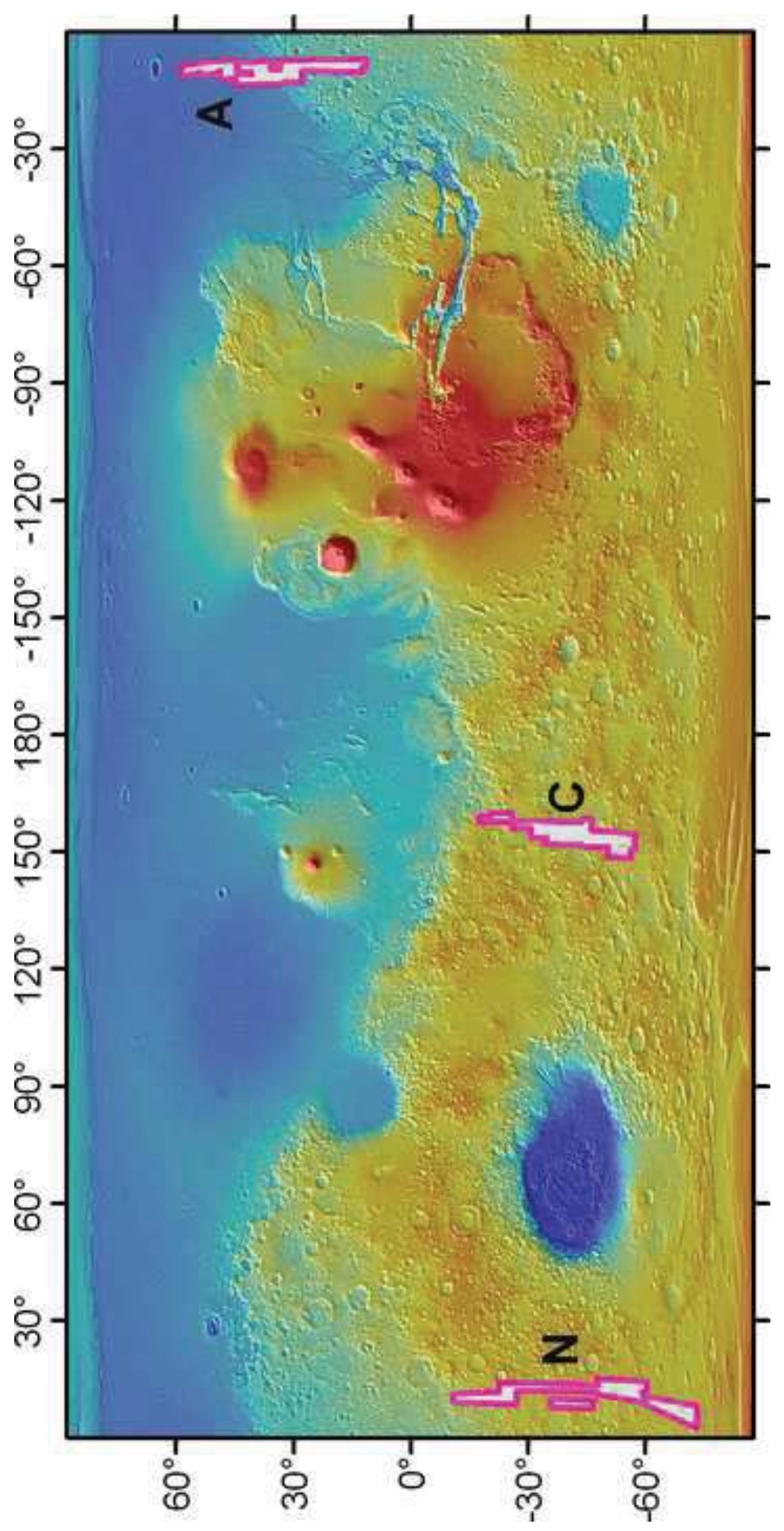




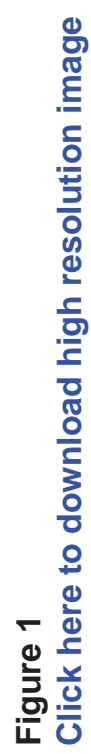

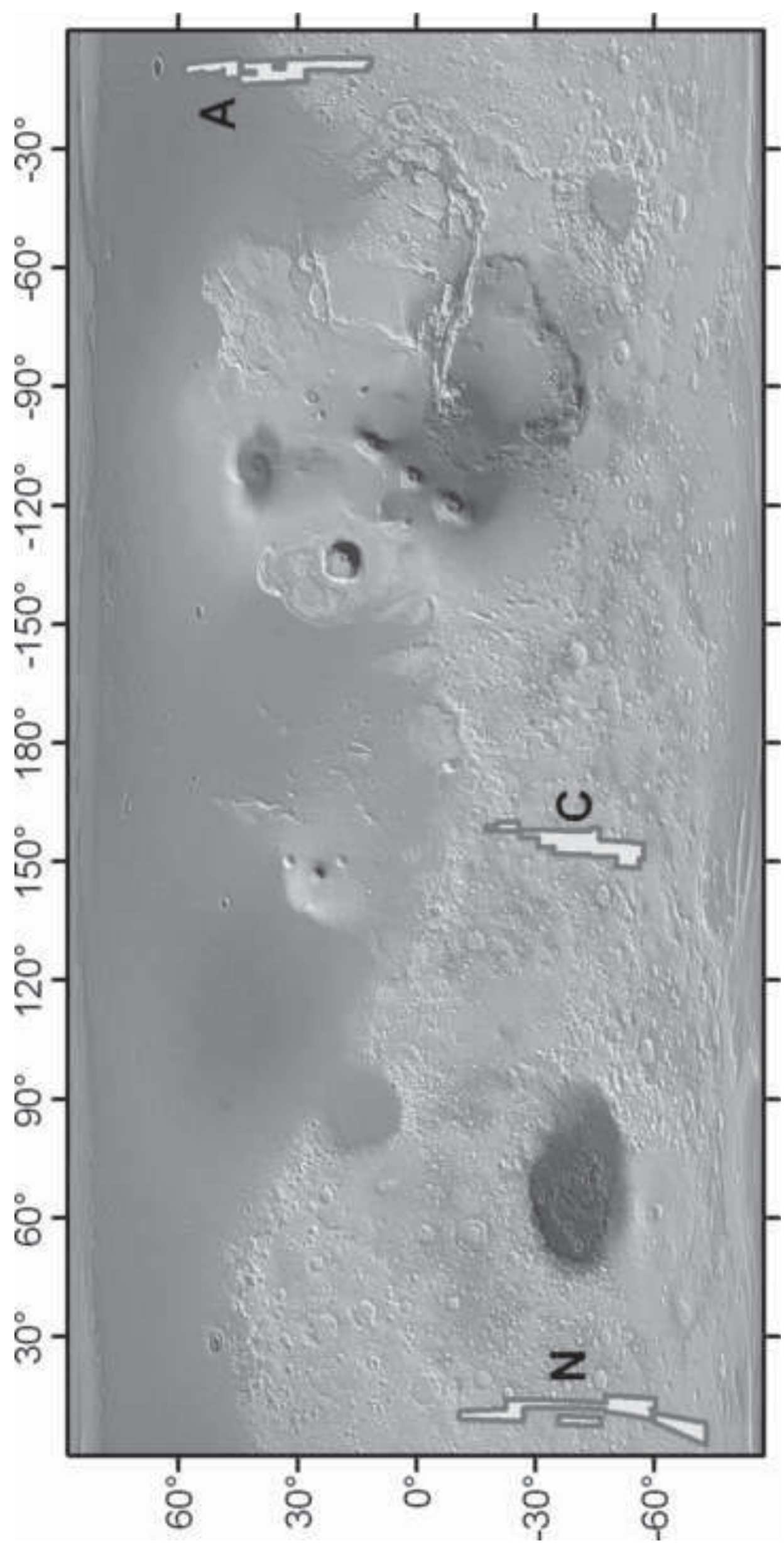




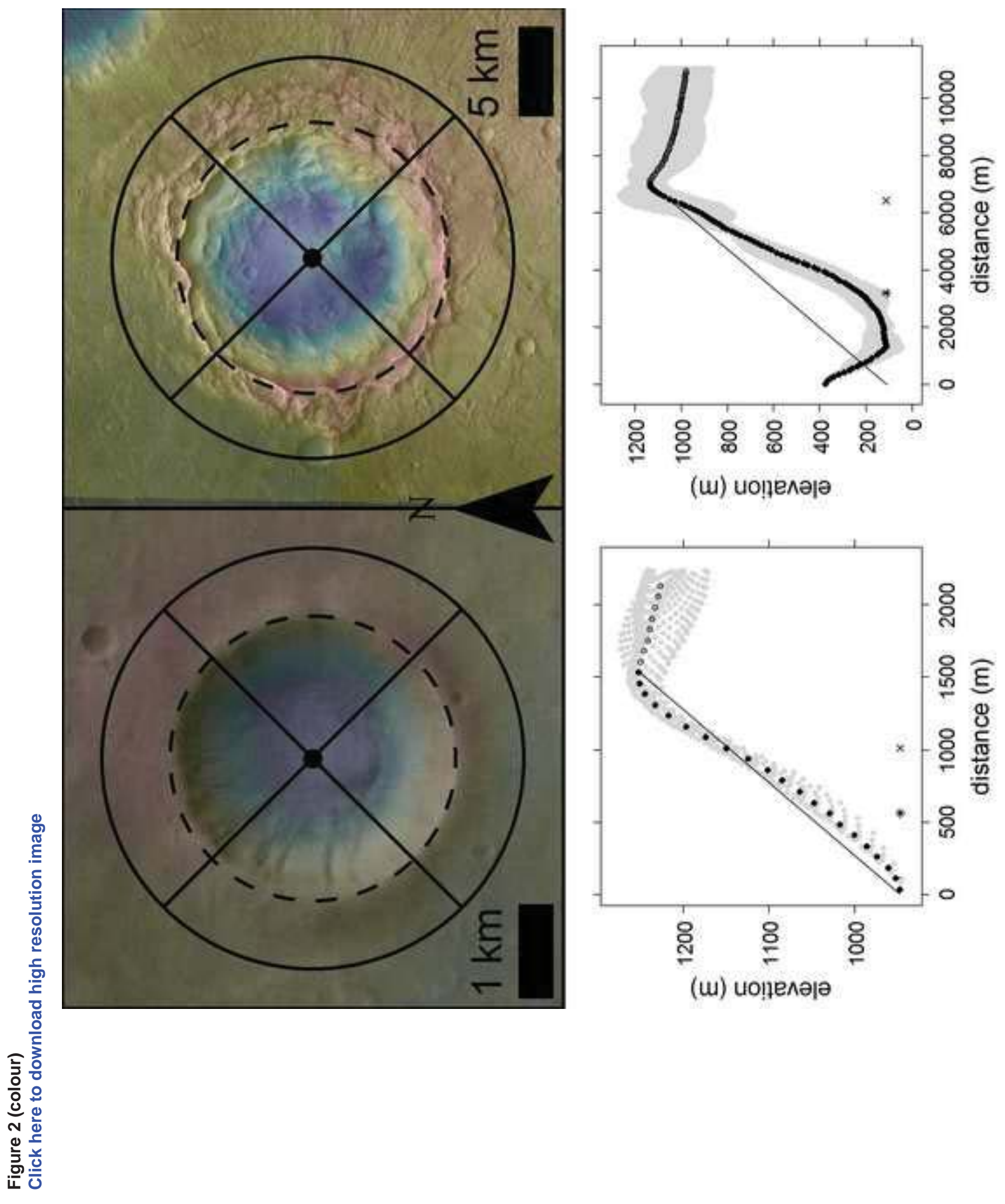




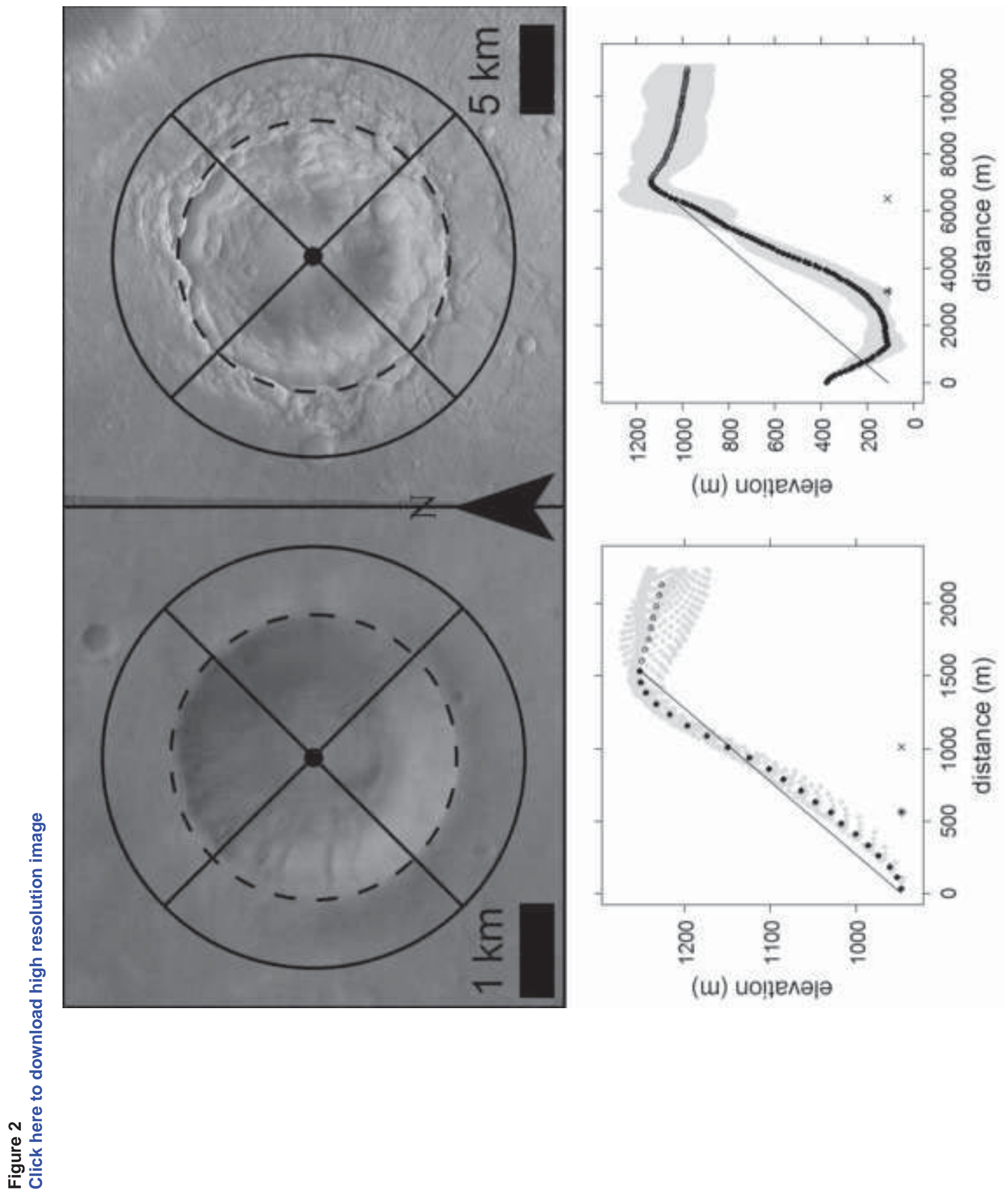




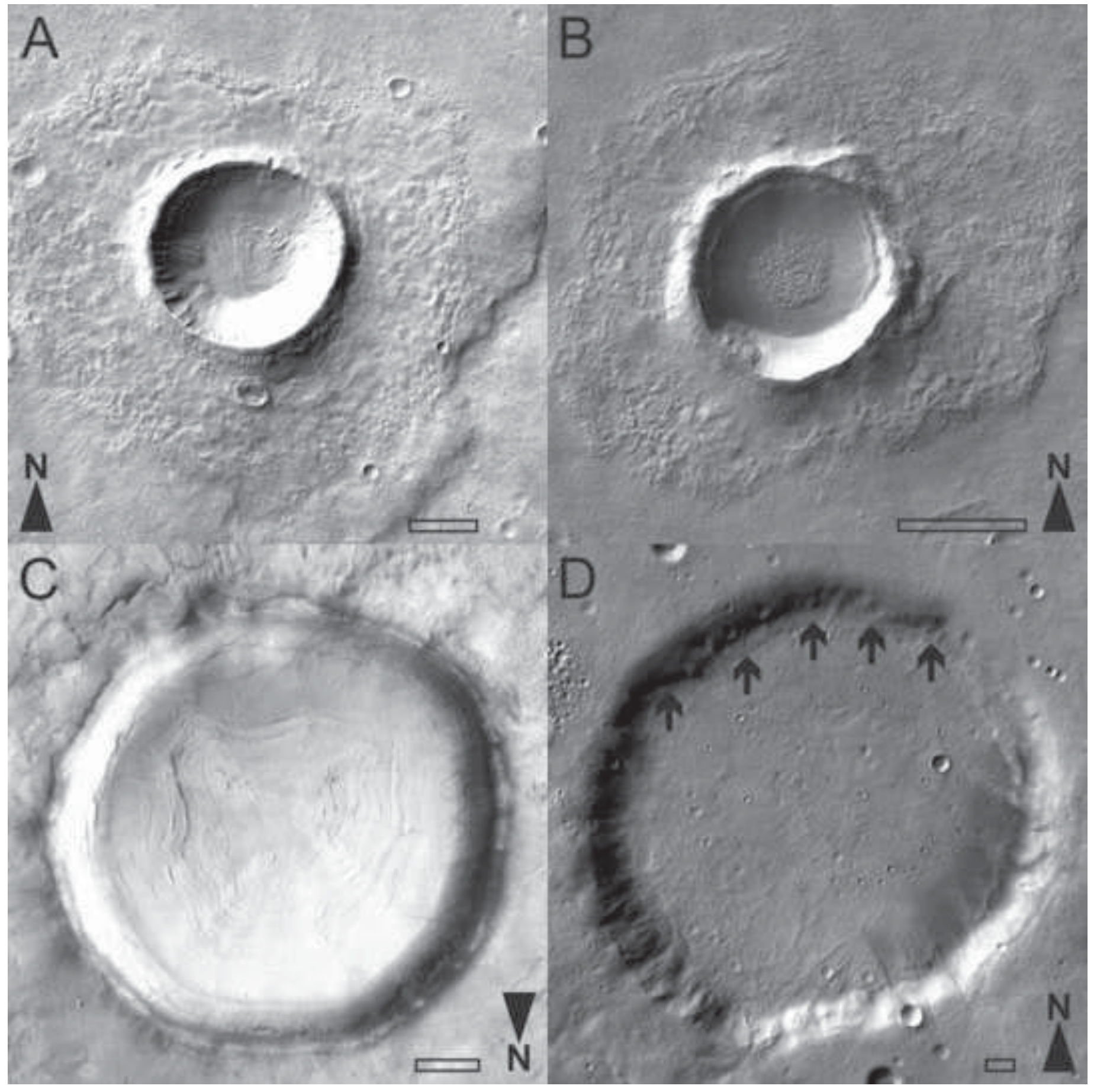


Figure 7

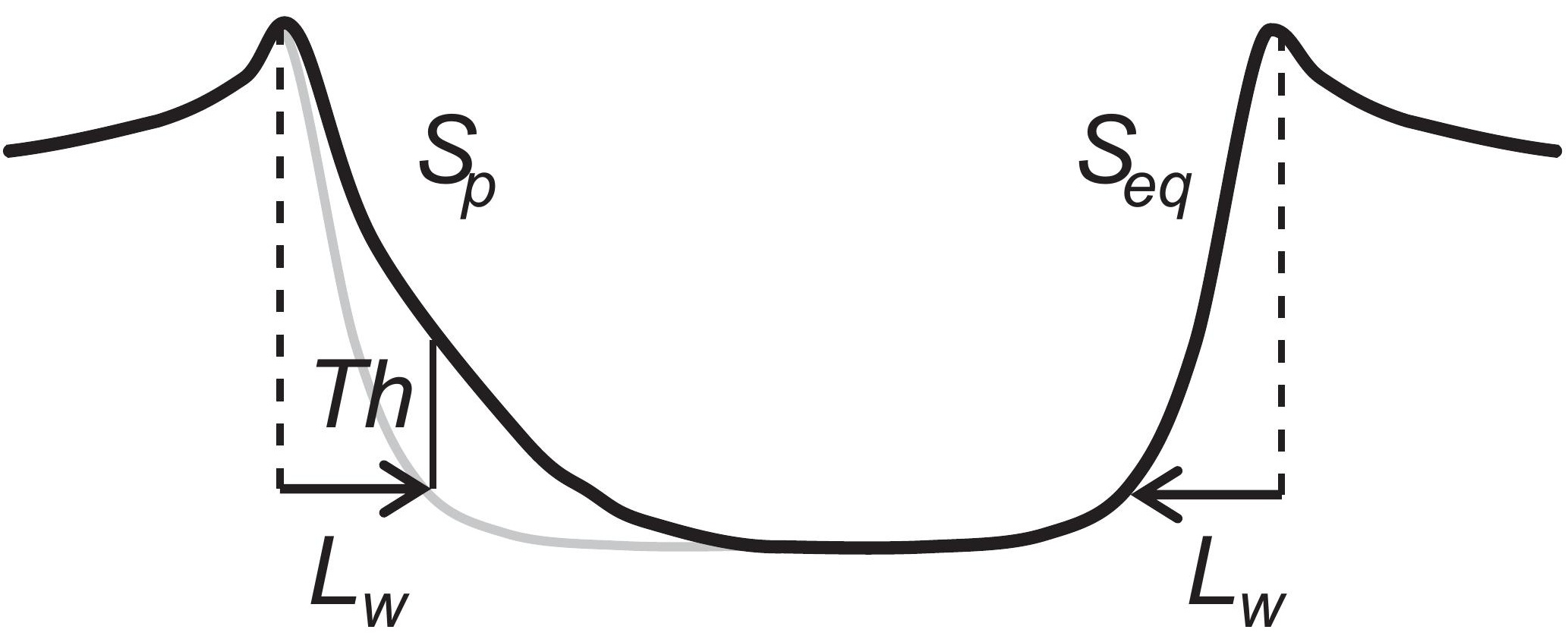




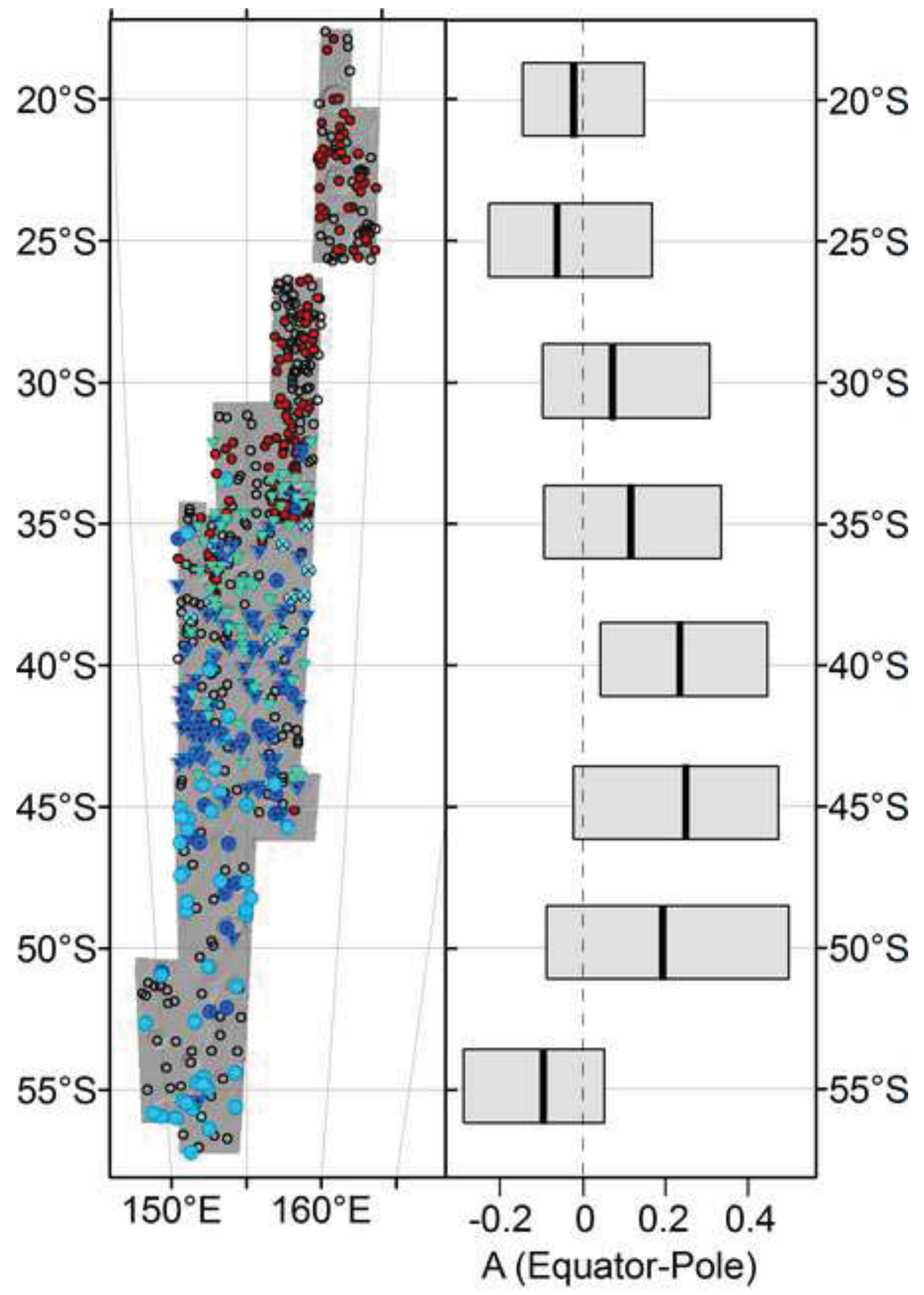

Crater Deposits: - equator-only - everywhere

- unknown \& floor-only pole \& equator

- none pole-only $>$ pole \& floor 


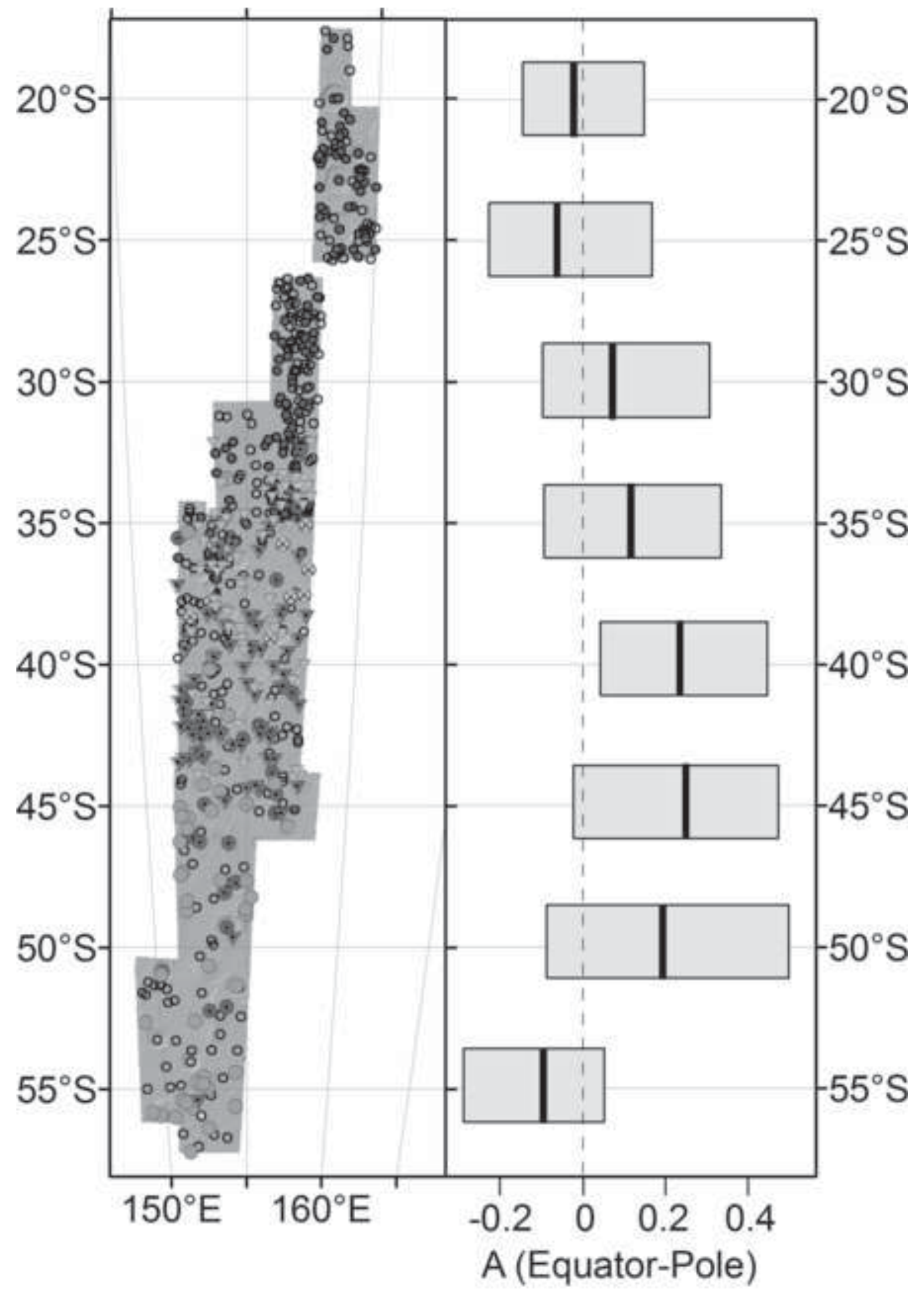

Crater Deposits: - equator-only - everywhere

- unknown \& floor-only pole \& equator

- none pole-only $>$ pole \& floor 